\title{
Discussion on the Competence-oriented Education Concept and Reform of Instruction Mode
}

\author{
Li He \\ Kunming Metallurgy College, Kunming, Yunnan, China, 650033
}

Keywords: competence-oriented education; vocation; instruction mode

\begin{abstract}
With the continuous growth of science and economy, education has gradually been one of the most important tasks of our country. At present, most of higher vocational colleges have gradually paid more attention to the competence-oriented education and cultivated the occupation ability of students in order to improve their comprehensive quality. The paper herein states the basic concept of competence-oriented education, discusses related course development, analyzes course design and action model and then proposes some proper and reasonable advice on the detailed reform method.
\end{abstract}

\section{Introduction}

As far as the current development is concerned, vocational education should not only provide students with related professional knowledge but also help them carry on their occupation directly after graduation from the perspective of professional post for meeting the basic needs of industry development. For the achievement of the purpose, teachers of vocational schools should transfer their own concepts, innovate the model of instruction and integrate the value of competence-oriented education with daily teaching.

\section{Basic Concept of Competence-oriented Education}

The competence-oriented education mainly refers to having great understanding of the detailed change of instruction that may directly have influence on the transformation of thinking model when conducting teaching activities. And the so-called concept of competence-oriented education refers to designing courses on the basis of the future vocational development of students. There are two aspects that should be considered when designing. One is what the course can provide for students and the other is whether there occurs another better way for students to stimulate them to accomplish the learning targets. The course design based on competence, compared with traditional course system, has extremely huge difference, which boasts great meaning to the improvement of comprehensive quality of students.

\section{Major Model of Course Development}

Courses themselves are the major elements of teaching activities and they can fully express the idea and concept of education, so currently it becomes extremely important to design the content of related courses based on this education philosophy. In the process of the reform of current vocational courses, some social-work-oriented courses have gradually been the main trend. These courses are extracted from the social works and then applied to the teaching, which will stimulate the improvement of comprehensive quality of students. Moreover, these kinds of courses can provide samples for reference for the design of competence-oriented courses ${ }^{[1]}$.

\section{Basic Design of Competence-oriented Courses}

The extraction of competence goal will decide the quality of courses in some extent while the goat vehicle may directly influence whether the course will succeed or not. Since the embodiment 
of competence is rather abstract while the entire process to have access to competence is really concrete. Generally speaking, the kind of competence training can be divided into several parts as example analysis, individual item of competence and comprehensive item of competence. All the vehicles that can express the competence-oriented education concept and cultivate the comprehensive competence of students can be regarded as superior ones.

\section{Reform of Action-oriented Instruction Mode}

Action-oriented mode can also be regarded as one model of instruction, which also means it is the model of instruction that is mainly driven by the action. In real teaching, it emphasizes the subjective value of students and the guidance value of teachers, as a result of which, analytical ability and capability of solving problems of students should be cultivated. Generally speaking, we should set different courses for students to lead them to gradually accomplish the courses and further realize the teaching goats. So, the relations among the methods, the competence-oriented education concept and the model of practical instruction can be described as that teachers should teach based on the competence-oriented education concept, set up related courses on the basis of the concept and further teach courses based on the action-oriented model.

All the teaching work should be conducted on the basis of the cultivation of competence of students, but competence itself can't be gained just by instruction but gradually acquired through the long-term training. So, the whole process of education is extremely important, which means teachers should work hard on guidance, master each detail of the status of study and finally improve the quality of courses ${ }^{[2]}$.

\section{Related Methods of the Detailed Reform of Instruction}

In the detailed process of the reform of instruction, most of the teachers express students of vocational school lack of learning consciousness and learning foundation, which is also the practical situation that the entire vocational education should face. With time going on, this kind of problem may be more and more serious. However, the market has its higher and higher demands for talents, which also leads to the worse and worse social adaptability of students of higher vocational school. Considering this problem, the current vocational education should be reformed, which asks teachers of higher vocational school to reform from aspects of the decision of competency standard and design of vehicles and teaching process. For that, there will be three teaching methods that can be tried to stimulate students to be more interested in the classroom teaching and help improve the quality of course.

\subsection{Achievement-based teaching method}

The so-called achievement teaching method refers to that it can bring corresponding achievement to students in the learning process of each class. Therefore, it requires teachers should design the teaching goat from the perspective of students' learning status according to the feature of the differentiation of students' basic knowledge to adapt hierarchical teaching that proposes different demands for different students and designs corresponding learning tasks for students. Specifically speaking, for students with poor degree of learning, teachers can require them to just finish the learning of basic knowledge; for students with mediocre degree of learning, teachers can require them to finish some expansive learning after the basic learning; for top students, teachers should put forwards higher demands to satisfy their desire for knowledge. Thus, all the students can finish their learning tasks effectively and enjoy the fun of learning, which can gradually help enhance the interest of learning.

\subsection{Problem-based teaching method}

The so-called problem-based teaching method mainly refers to the classroom teaching will start step by step from the problems of classroom teaching. It may lead students to raise questions, find problems, solve problems and finally find what really matters on their own, which is the process of 
spiral escalation. For that, teachers should ask students to do the preview before class, have rough knowing of what will be learned on the next day, list the knowledge points they don't understand and learn with questions in class. Meanwhile the questions set by teachers should be instructive but not too straightforward, which can trigger students to think deeper and improve the validity of knowledge learning ${ }^{[3]}$.

\subsection{Fun-based teaching method}

The so-called fun-based teaching method mainly refers to it can present feature of fun and make students enjoy the classroom teaching, change their initial attitude towards learning and dedicate themselves to learning activities when designing the problems and tasks. For that, teachers should innovate from the aspect of curriculum design. The traditional methods as student management system and dormitory management system apparently can't stimulate enthusiasm of students, so they may have to introduce some methods as lyrics management, video playing and schedule reminder. These methods are close to students' personal life and can replace the traditional ones by related practical items.

\section{Conclusion}

As far as all mentioned above, when designing the higher vocational courses based on the competence-oriented concept, we should stimulate the improvement of work ability of students on the basis of competence and further make them comprehensive talents who can meet the needs of society.

\section{References}

[1] Liu Jianbo. Research on the reform of stage-concept as " $3+4$ " cultivation of secondary vocational school to bachelor degree of accountancy based on the competence-oriented education concept[J]. Journal of Weifang College, 2015,15(5):96-98.

[2] Kou Xiangliang. Research on Research on the reform of stage-concept as " $3+4$ " cultivation of secondary vocational school to bachelor degree based on the competence-oriented education concept[J]. Global Market Information Guide, 2017(39):80-80.

[3] Yin Zhidong, Cai Liping, Meng Mei etc. Research on construction of participatory teaching model of P.E. based on competence-oriented education concept [J]. Sports Science Research, 2015,26(3):119-121. 